\title{
Las series y el Sueño Americano. Nostalgia y pervivencia de un imaginario suburbial
}

\author{
Ariel Gómez Ponce \\ Universidad Nacional de Córdoba, Córdoba, Argentina \\ ORCID: https://orcid.org/0000-0001-8830-9544
}

\section{Resumen}

En la memoria estadounidense, la vida en los suburbios permanece como un contexto de prosperidad, crucial para ese imaginario conocido como Sueño Americano. No obstante, se trata de un escenario idílico que las series televisivas vienen cuestionando, incluso desde el florecimiento mismo de este modo de habitar. Este artículo propone un estudio de ficciones de mediados de siglo pasado que han aplicado a una lectura disfuncional del Sueño Americano: ello es, narrativas que lograron ilustrar las contracaras de la homogeneización y la estandarización, revelando el orden de lo cotidiano como un precario simulacro. Se trata, empero, de motivos ideológicos que las producciones más contemporáneas parecen releer como una "nostalgia": categoría que la teoría de Fredric Jameson desarrolla a los fines de interpelar formas artísticas donde las ideas del pasado se elaboran de manera alegórica, en tanto imágenes residuales sobre las cuales el presente impone otra línea de significación. La propuesta sostendrá que las claves de esta nostalgia deben rastrearse en el proceso de suburbanización de posguerra, enclave que no puede pensarse fuera de un incipiente capitalismo tardío cuya reproducción en serie planificó tanto un proyecto urbanístico como la conformación de subjetividades. En diálogo con los aportes de Jameson, el artículo pretende exhibir cómo, tempranamente, la televisión masiva ha funcionado no solo como un modo de producción estética, sino además como una institución social con fuerza crítica.

\section{Palabras clave}

Series de TV; Sueño Americano; Imaginario suburbial; Fredric Jameson; Nostalgia 


\section{Introducción: Acerca de una nostalgia televisada}

Poco antes de la segunda elección presidencial de George W. Bush, la cadena ABC dio luz verde a Desperate Housewives (2004-2012), serie televisiva dedicada a narrar la vida de cinco amigas en los suburbios. Para aquel entonces, las mujeres de la pantalla chica habían enseñado que la mirada femenina no era tanto una posibilidad como una necesidad cultural y, durante varios años, Sex and the City (1998-2004) encabezó esta ruptura televisiva de los cánones. Pero, en detrimento de la vitoreada serie protagonizada por Sarah Jessica Parker (donde el lujo, el sexo y el devenir después de los cuarenta enmarcaban el relato femenino), Desperate Housewives trabajó la historia de un grupo de mujeres que debían afrontar pequeñas vicisitudes de lo cotidiano. Incluso, parecía recordar que la vida en los suburbios era aún un escenario posible, lugar donde todavía permanecían esquirlas de lo idílico y de un periodo de abundancia y tranquilidad para la comunidad estadounidense.

Figura 1- Imágenes promocionales de la serie Desperate Housewives (Serie de Televisión)
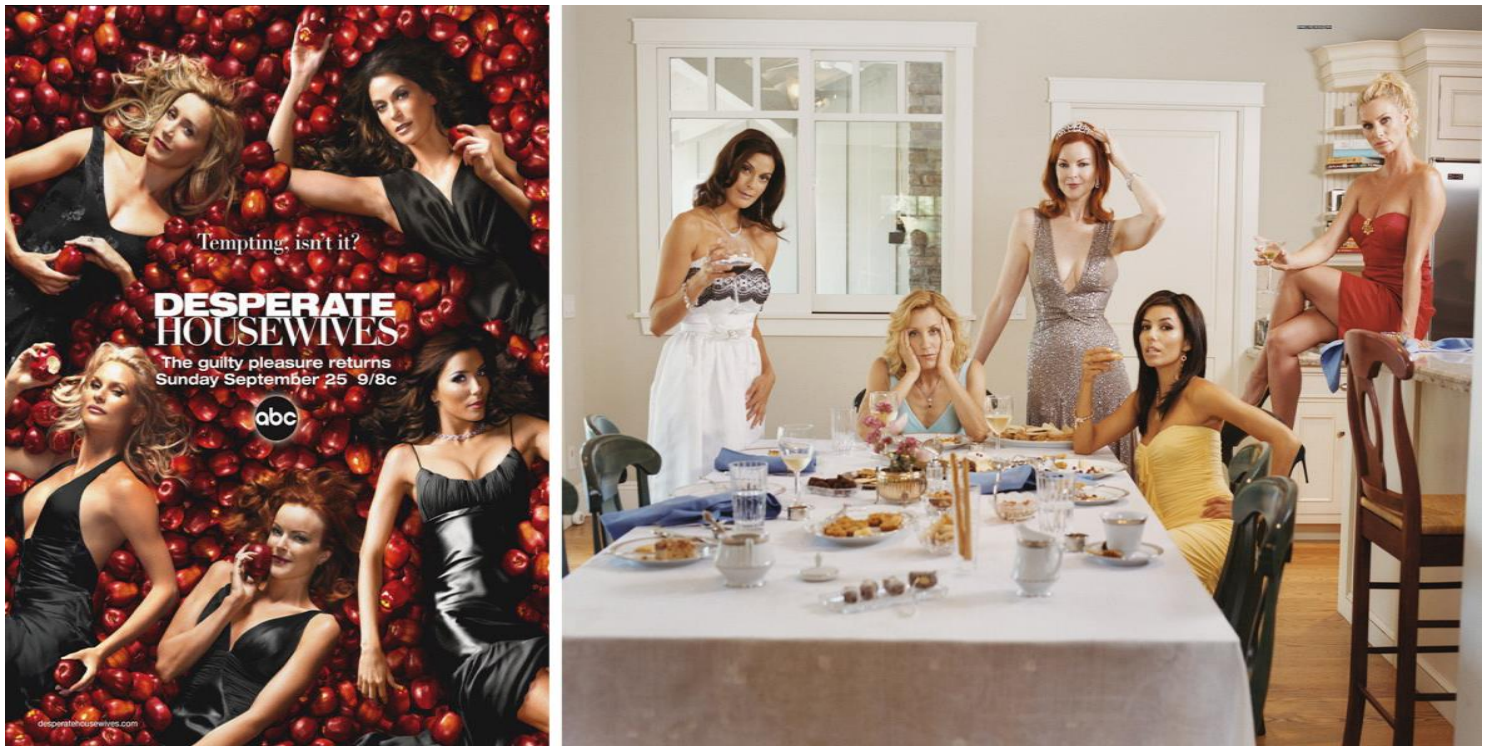

Fuente: Universal Studios, ABC Studios (2005).

No hay aquí intención de abordar esta serie señera, pero creo que algunos datos pueden contextualizar los derroteros que pretendo recorrer. En una lectura superficial, esta narrativa emergió como una bocanada de aire, reafirmando lo tradicional en unos Estados Unidos agobiados por el debate mediático de la Guerra contra el Terrorismo y la invasión de Irak, acontecimientos que vinieron a poner en crisis valores fundamentales del país. En el mundo de Wisteria Lane (nombre que recibirá el barrio suburbial), las identidades se 
hallaban claramente delimitadas, los peligros habían sido erradicados de la vecindad, y la felicidad de las familias yacía en los hogares homogéneos y repletos de lujos domésticos. 0 eso, al menos, en la superficie. Pues, como muchas otras series de la época, Desperate Housewives insistía en mostrar el interior de matrimonios erosionados por los engaños y la infidelidad, el pesar de las mujeres inconformes en su rol de madres con maridos frustrados por las privaciones económicas, los interines de una ostentosa competencia entre los vecinos $y$, en pocas palabras, el modo en que una sociedad estadounidense esquiva su declive, resguardándose de manera insistente en los telones del simulacro.

Algunas semanas después del estreno de este seriado, en una extensa pero interesante cita, la periodista Dana Stevens sugirió que

Desperate Housewives le pega una mordida a la roja y brillante manzana de los suburbios y encuentra un gusano dentro. ¿Alguien se sorprende? Después de todo, Hollywood ha estado explorando este territorio: el contraste entre las superficies coloridas de la vida de la clase media y el miedo, la lujuria y la furia que se agitan debajo. Pero hay, al menos, un problema: el plácido estilo de vida suburbano que muestran series como Desperate Housewives, un mundo en el que las mujeres, sin quejarse y dentro de una lujosa mansión, se quedan a la espera de ser mantenidas por sus laboriosos maridos, ya no existe. ¿Por qué estamos desesperados por satirizar una parte del "American Way of Life" que, rápidamente, está desapareciendo? ¿Esta ola de ficciones es solo una nostalgia suburbana disfrazada? ${ }^{1}$ (STEVENS, 2004, doc. s.p., la traducción es nuestra).

De la opinión en cuestión, se desprende que, si bien Desperate Housewives puso la vida suburbial en el centro de la escenografía serial, también es cierto que muchos otros recorridos estéticos se habrían hecho eco de este particular contexto. Porque, a ciencia cierta, el suburbio es uno de los entornos preferidos de las series televisivas, y ha dado lugar a un sinfín de relatos que buscan deslindar los sentidos escondidos en este espacio crucial para la cultura de los Estados Unidos.

Desperate Housewives no funciona más que como puntapié inicial para este trabajo, por cuanto replica un modo en que la ficción, durante más de medio siglo, ha estado desdibujando los contornos de este imaginario tan tradicional ${ }^{2}$. Desde el clásico filme The Stepford Wives (2004) hasta la más reciente Secret and Lies (2014-2015), las ficciones seriadas parecen estar obsesionadas por develar la falacia del estilo de vida norteamericano,

\footnotetext{
1 Todas las traducciones son mías.

${ }^{2}$ Circunscribo esta concepción, por lo demás recurrente en las humanidades y ciencias sociales, a Cornelius Castoriadis y su propuesta de un imaginario social instituyente en tanto organización casi inasequible de sentidos, significados y prácticas sobre la cuales descansa la identidad de una comunidad. Al respecto, véase CASTORIADIS, 2000, p. 92-112.
} 
lógica que lleva al extremo el título la exitosa producción de HBO, Big Little Lies (20172019). En lo estético, estribaría una óptica para que el espectador pueda inmiscuirse en la cotidianeidad estadounidense y oír sus confesiones desde la posición de lo íntimo, operación que también Suburgatory (2011) capta a todas luces, indicando que el suburbio puede devenir una suerte de purgatorio social. Pero, ¿por qué insistir en contar la vida suburbial, pero en clave derrotista? ¿Por qué las series friccionan la perfección y la decadencia social dentro de los suburbios? ¿Es el Sueño Americano el marco de esta utopía inasible y la ficción, un lugar privilegiado para explorar sus quiebres y los vacíos que las subjetividades intentan encubrir? ¿Cuál es, efectivamente, el vínculo entre la serie de TV y la vida suburbial?

En este trabajo, sostengo que un terreno fértil para acercarme a estos interrogantes yace, casualmente, en uno de los cuestionamientos que desliza Dana Stevens: ello es, un pathos nostálgico que se camufla en los derroteros de un orden cotidiano llevado a la ficción. En tal sentido, el presente artículo propone un acercamiento en vistas de organizar y clasificar algunas premisas que permitan poner en cuestión el modo de vida suburbial en su representación televisiva y masiva. Para dar cuenta de ello, recuperaré la noción de nostalgia propuesta por Fredric Jameson (2012a), categoría pertinente para explicitar las relaciones semióticas que el presente mantiene con el pasado, como también los derroteros que ha atravesado aquello que el pensador sintetiza como un giro espacial. Lo me propongo aquí, en diálogo con la teoría narrativa del filósofo marxista, es bucear por los modos de significación que han operado sobre las series de TV, introduciéndome directamente dentro de aquella matriz de emergencia que estos productos televisivos y el suburbio comparten: ello es, la década de los cincuenta.

Si, como afirma Jameson, “[...] para los estadounidenses al menos, la década de 1950 sigue siendo el más privilegiado de los objetos de deseo perdidos" (2012a, p. 56), debo ser capaz, entonces, de hallar ciertos motivos que han operado sobre la época, determinando la comprensión de aquello que esta sociedad define como un Sueño Americano3 ${ }^{3}$. Entiendo, entonces, que una exploración por series emitidas a medidas de siglo pasado puede brindar, detrás de sus tramas, claves ejemplares para problematizar las derivas ideológicas de un imaginario que ha modelado, históricamente, la cultura de los Estados Unidos.

\footnotetext{
${ }^{3}$ Sobre este lugar común de la cultura estadounidense, me he abocado en indagaciones previas, en las cuales recupero el modo en que las series televisivas problematizan este basamento ideológico en torno al cual congregan las grandes utopías del país norteamericano (GÓMEZ PONCE, 2018). Para una lectura histórica atenta, recomiendo el estudio realizado por Cullen (2013).
} 
Para dar cuenta de ello, el primer apartado de este artículo estará dedicado a revisar algunas premisas para repensar la construcción histórica del suburbio como modo de habitar estadounidense, desde un enclave fundación como la conquista del Lejano Oeste hasta la suburbanización de posguerra. En un segundo momento, me abocaré a realizar un recorrido que no pretenderá exhaustividad, sino que se ofrecerá como panorama de series antiguas que, atravesadas por una multiplicidad de operaciones, han dado forma al suburbio como contexto del Sueño Americano. En este trayecto, observaré cierta crítica en las series más recientes que ya aparece, de manera impensada, en los albores de la década de los cincuenta. Desde esta postura, la homogeneización, la estandarización, la precariedad de lo cotidiano y, principalmente, el simulacro serán motivos ${ }^{4}$ que han dado forma a la escenificación del Sueño Americano en los orígenes de la televisión, imágenes residuales que también navegan por los seriados actuales como estelas de sentidos pretéritos.

Por tal motivo, parto de lo descriptivo para tratar de vislumbrar los fenómenos que se van produciendo en esta reconstrucción de la idílica comunidad del suburbio, atendiendo a su configuración espacial como un lugar de operaciones culturales y económicas de mayor complejidad. Desde esta postura, la relación entre serie de TV y vida suburbial no puede ser pensada fuera de las condiciones de posibilidad que habilitan los derroteros del capitalismo tardío, allí donde la reproducción en serie planificó tanto un proyecto urbanístico como la conformación de las subjetividades.

Hablo, en otras palabras, de entender a la televisión como una "máquina de reproducción más que de producción" de modelos culturales (JAMESON, 2012a, p. 79). En tal sentido, retomaré una precisión metódica fundamental en Fredric Jameson (1989) para quien la única manera de pensar las narrativas masivas es captándolas en su advenimiento histórico: último horizonte de análisis que permite atender el modo en que la cultura repone soluciones imaginarias ante sus contradicciones sociales.

\section{La vida suburbana y los sueños del capitalismo tardío}

En la vida suburbana, se condensan un conjunto de motivos ideológicos que atraviesan, insistentemente, la diacronía de los Estados Unidos: el individualismo, el elitismo, la homogeneidad y el consumismo, los cuales congregarán dentro de un escenario

\footnotetext{
${ }^{4}$ Uso el término motivos en el sentido de figuras textualizadas y grandes unidades ensambladas que hacen a la organización argumental de los textos. Al respecto, véase ARÁN, 2016, p. 143.
} 
idílico, de aparente perfección e inclinación por la tradición y el nacionalismo (GÓMEZ PONCE, 2018). Por tal razón, este modo de habitar debe comprenderse a la luz de una matriz histórica y de un complejo modelo nacional que introduce una concepción particular de la cartografía espacial, al amparo de la cual debe atenderse toda puesta en escena suburbial del Sueño Americano.

$\mathrm{Si}$, desde los albores coloniales y el Acta de Hacienda formulada por Abraham Lincoln en 1862 hasta el New Deal roosevelteano, la posesión de una parcela de tierra es asumida como un derecho universal y un "emblema de la democracia" (CULLEN, 2003, p. 149), también es cierto que, desde sus inicios, Estados Unidos habría pautado otro modo de distribución territorial. En tal sentido, los estudiosos coinciden en sugerir que, en detrimento de otros procesos fundacionales (como Argentina, en donde la tierra conquistada se dividió en grandes latifundios), el naciente país norteamericano optó por fraccionar su espacio en pequeñas parcelas al cuidado de núcleos familiares, delegando en ellos una responsabilidad hacia la nación (BENDER, 2011). Esto puede observarse, por ejemplo, en el corolario a la Conquista del Oeste y en el intento por movilizar a los sectores bajos y medios, otorgándoles fragmentos de tierra a precios módicos. Al tiempo que responde al esfuerzo de una clase dominante por poblar las tierras adquiridas, esta lógica habría instaurado un espíritu nacionalista a través del cual el hogar deviene metonimia del país. Se trata de una operatoria que logra que cada sujeto devenga, en cierto modo, custodio de una fracción de la nación y responsable único de su lugar en el mundo, fijando así los cimientos de un liberalismo que se organiza con base en la propiedad privada y el individualismo (BOSCH, 2010).

De allí en más, este imaginario espacial alcanzará todo su esplendor entre 1945-1973, intervalo de la historia reciente que Fredric Jameson (2012a, p. 25) define como el "breve siglo estadounidense" 5 . Se trata de un fragmento temporal que amalgama la Pax Americana con una sociedad de la prosperidad, la abundancia y la utopía, poco antes de que otros impulsos utópicos (como los movimientos raciales, sexuales, ecológicos y anticapitalistas) tuvieran lugar en el país. Particularmente, será en este contexto cuando se emprenda una planificación urbanística a gran escala ante una nueva explosión demográfica (el Baby boom), contenida por un conjunto de políticas gubernamentales, tales como la profusión de

\footnotetext{
${ }^{5}$ Aunque se trate de un fenómeno que nace en el periodo de entreguerras (BAIRATI, 1987), este modo de habitar cobrará visibilidad recién en el transcurso de la Guerra Fría, cuando las grandes metrópolis comienzan a desprender sus límites a la forma de pequeños barrios ubicados en sus periferias (DUHAU; GIGLIA, 2008). Y si bien el ritmo de este desplazamiento urbano se ralentiza en la Europa de posguerra, logrará expandirse homogéneamente por todo el continente americano, orientado por el modelo estadounidense. Al respecto, Véase GONZÁLEZ ORDOVÁS, 2000.
} 
créditos para la adquisición de viviendas, la creación de carreteras y autopistas, o el incremento en la producción y el comercio de vehículos, entre otros.

Casualmente, en esta "suburbanización de posguerra" (CULLEN, 2003, p. 153), emergerá aquella forma estereotipada que el arte se esmera en refractar: ello es, la configuración idealizada donde los hogares, habitados por formas tradicionales de la familia, son construidos bajo un modelo de producción en serie, propio del capitalismo tardío. Por ello, entender el estallido de este modo de habitar es, asimismo, interrogarse sobre modificaciones socioeconómicas con impacto directo en la concepción material y simbólica de los espacios tradicionales, característica estructural de los cincuenta (y de todo el posmodernismo) que Jameson (2012a) sintetiza como un giro espacial.

Al respecto, el filósofo marxista advierte que esta década se caracteriza por la estandarización, como un intento de contención frente al fuerte reposicionamiento de fronteras sociales y económicas (procesos de descolonización, movimientos sociales, dispersión de capitales en grandes corporaciones multinacionales). Ante esta suerte de diáspora cultural, la forma capitalista de producción en serie aparece como una solución expeditiva, mientras que los barrios residenciales (con sus hogares dispuestos homogéneamente y sus modelos de prole nuclear, replicados de manera casi serial) eliminan la diferencia, reforzando todo un imaginario "[...] en torno a la valorización de la familia como célula fundamental de la sociedad, y de los lazos de vecindarios posibles a partir de la homogeneidad social" (DUHAU; GIGLIA, 2008, p. 265).

Sin embargo, junto a Eduardo Nivón Bolán (2003, p. 19), diría que esta exaltación de lo igual supone "una alternativa elitista para dar la espalda a los males de la ciudad", en tanto tendencia clasista que aísla la comunidad en un entorno límpido, aparente cuadro utópico. Incluso, esta estandarización colabora también con otra segregación, puesto que el espacio laboral (la ciudad) comienza distanciarse de aquel doméstico y familiar, dando lugar a una comunidad donde lo público y lo privado comienzan a separarse en términos físicos.

Otra manifestación sensible que Jameson (2012a) señala en este giro espacial se halla en diálogo con el auge de una sociedad de consumo, impulsada por el crecimiento económico de posguerra y por un conjunto de estrategias de corte capitalista - como la reducción de horas en la jornada laboral y el estímulo fiscal para la compra masiva de bienes domésticos (GONZÁLES ORDOVÁS, 2000, p. 187-188). Se trata, además, de un enclave que se verá reforzado por una nueva discursividad: aquel mundo publicitario que, en términos de Anna Tous-Rovirosa (2015), deviene el artífice del Sueño Americano. En efecto, basta observar las emblemáticas publicidades de reconocidas empresas como Coke, Lucky Strike o 
Kodak para entender esa articulación donde la figuración del ideal del hogar se engarza con la dimensión de mercado y su modelo de producción en serie. En dicha coyuntura, casas, vehículos, electrodomésticos y otros pequeños lujos de la clase media (como la televisión) suponen, más que bienes que facilitan la cotidianeidad, emblemas que materializan el Sueño Americano y, en opinión de Duhau y Giglia, “[...] funcionan como elementos de control social que refuerzan la preservación de la homogeneidad de sus habitantes" (2008, p. 265).

Figura 2 - Publicidades de los años cincuenta en donde el Sueño Americano y el modo de habitar suburbial son fuertemente realzados.
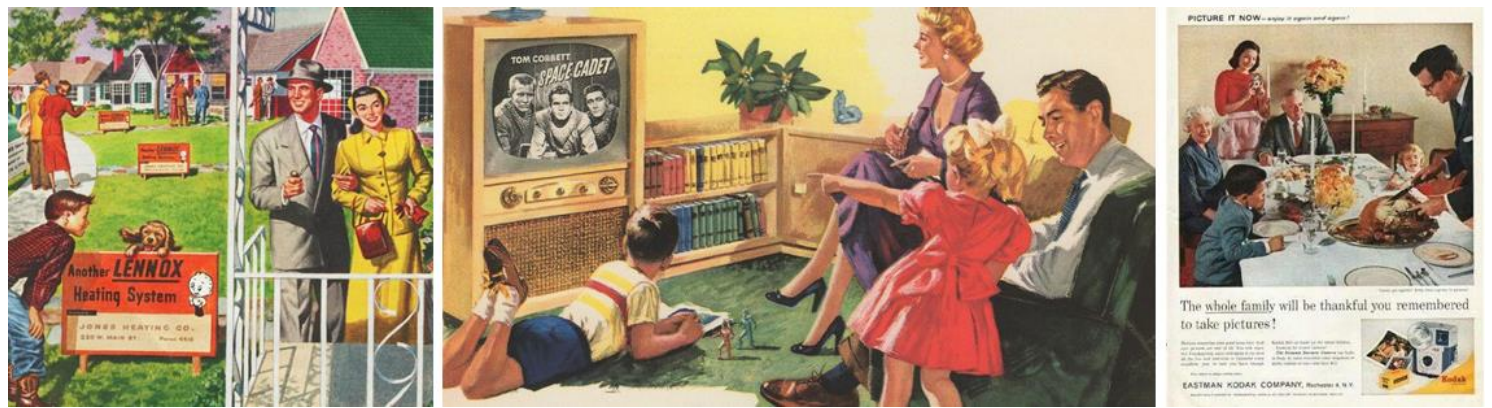

Fuente: Catálogo digital Envisioning the American Dream (2021). EDELSTEIN, Sally (comp.). Estados Unidos, 2021. Disponible en: https://envisioningtheamericandream.com/

Como se comprenderá, la vida suburbial aplica a innovaciones no tanto en la distribución espacial y las formas de consumo, como en la construcción misma de las subjetividades colectivas, motivo por el cual el Sueño Americano no puede ser pensado si no es trazando también sus contrapuntos sociales. De lo se trata es de reafirmar que la contracara de este imaginario onírico: ello es, "[...] un exceso de optimismo tras el que anidan, negados, los grandes fantasmas de la sociedad norteamericana: la soledad, el desarraigo y la presión de lo que es idéntico y estandarizado" (PINTOR IRANZO, 2015, p. 109). Pues, bajo la aparente perfección de la escenografía en los suburbios, se esconde un carácter tensivo con efectos directos sobre las subjetividades, inserto en una cotidianeidad que no deja de mostrar su precariedad. Y, casualmente, es allí donde el quiebre no reparativo del Sueño Americano adquiere sus rasgos más visibles: el hastío de la comodidad, el fracaso del ideal matrimonial y las disputas de las identidades (GÓMEZ PONCE, 2018). Desde esta lectura, el entorno doméstico supone un terreno fértil para interrogarse acerca de la forma en que la comunidad toma "conciencia de las fisuras del Sueño Americano" (PINTOR IRANZO, 2015, p. 110, el subrayado es nuestro).

$\mathrm{Al}$ respecto, vale destacar las derivas de los roles sociosexuales en los cincuenta, principalmente en esa imagen masculina erosionada por la Gran Depresión y, luego, por la 
extensa ausencia a causa de la Segunda Guerra Mundial. Como una antesala de la emancipación femenina, este periodo acentúa un predominio de lo femenino tanto en el ámbito público como doméstico, dado que la mujer habría tenido que asumir los vértices que organizan el esquema tradicional de la masculinidad hegemónica: progenitora (paternidad), proveedora (patrimonio) y protectora (seguridad) (GIL CALVO, 2006). Incluso, se puede intuir que, al amparo de una presión imperante por modelar la familia como refugio de perfección, este desplazamiento de lo femenino entró fuertemente en fricción con el retorno masivo de los hombres, quienes vuelven agobiados por las reminiscencias de la guerra, una prolongada expatriación y la incertidumbre de una cultura que cambia vertiginosamente.

Pero, según la lectura de Fredric Jameson (2012c), esta precariedad doméstica trataría con un escenario aún más amplio, pues supone un rasgo sintomático de la sociedad del simulacro, donde las apariencias y la especulación aparecen como respuestas ante una crisis burguesa y su "disolución" en el entramado del capitalismo tardío. Dicho de otro modo, aquella competencia capitalista que dio lugar a "un ego adquisitivo y agresivo, y a una identidad poderosa y edípica" se vio reemplazada por la vulnerabilidad de un pequeño burgués que se deteriora bajo las instituciones a gran escala y que ha perdido la confianza en el aparato político-económico (JAMESON, 2012c, p. 41). Quizá, por ello, el filósofo clausura este utópico "siglo breve" en 1973, cuando la Crisis del Petróleo y el estallido del escándalo Watergate (y, tiempo después, la dimisión de Richard Nixon) muestran la fragilidad de una sociedad estadounidense, abrumada por el miedo nuclear y desgastada por el fracaso en Vietnam. Como un signo epocal de este complejo entramado, la aparente perfección de hogar aparece, sin lugar a dudas, como un campo privilegiado para mantener los telones del simulacro y ocultar las tensiones de un orden subjetivo que ha entrado en un fuerte dinamismo.

Con todo, este apartado pretendió dar modesta cuenta del imaginario suburbial, subrayando algunos de los rasgos constitutivos que se harán eco en la ficción seriada. Pero quisiera llamar la atención sobre un aspecto final. Apropiándome de las palabras de Jameson, diré que “[...] la lista no está compuesta por realidades o hechos históricos (a pesar de que sus elementos no son inventados y son, en cierto sentido, 'auténticos'), sino más bien por estereotipos, por ideas sobre hechos y realidades históricas" (JAMESON, 2012b, p. 37). Desde esta perspectiva, la vida en los suburbios debe afrontarse como un pasado estereotípico sobre el cual las formas artísticas trazarán otra línea de sentidos. Ello responde a lo que Jameson define como una nostalgia, categoría pertinente para afrontar la 
historicidad no tanto en términos de una representación inmediata del pasado, como de la relación que el presente mantiene con este. Consecuentemente, sugiero que, en un intento por reconstituir la historia mediante la óptica del hoy, los motivos del imaginario suburbial aparecerán como imágenes residuales que aplican a este pathos nostálgico. Y, siguiendo la invitación de Jameson (2012b, p. 40), emprenderé una exploración a la búsqueda “[...] de todos los atributos con que hemos dotado a la época, muchos de los cuales parecen provenir, de forma muy precisa, de sus propios programas televisivos", lo cual me coloca en otra intersección productiva.

\section{Una breve genealogía por el suburbio televisivo}

El ligamen entre la serie televisiva y el "siglo breve estadounidense" es mucho más profundo de lo que, a simple vista, puede parecer. Vale recordar que el crecimiento económico de la época colaboró no solo con el incremento en el consumo de artículos domésticos, sino también con la creación de tecnologías relacionadas con el orden mediático (JAMESON, 2012a, p. 25). Se trata de la explosión masiva de los medios de comunicación que tendrá como resultado la circulación doméstica de la información global, la "reducción" de las distancias entre los confines del mundo y la mercantilización de estilos de vida, prácticas que dan cuenta de un nuevo sistema internacional. Un caso ejemplar se halla en una de las primeras interacciones entre estética y mercado que afronta la televisión: las soap-operas (cuya traducción sería "óperas de jabón", clara ironía de la elite cultural para describir este fenómeno masivo), ficciones seriadas que funcionaban como "excusa" para incentivar la compra de productos de limpieza (HAGEDORN, 2001, p. 37-39). De allí que Jameson (2012a) sostenga que la televisión (como también el cine) supone un lenguaje cultural que no debió adaptarse al capitalismo tardío, en tanto nace de su mismo entramado. En detrimento de otras formas artísticas como la literatura o la pintura, la televisión es coetánea a este paradigma socio-económico, posicionándose no solo como modo de producción estética sino, más bien, como institución social que "desvela de manera inesperada la materialidad producida de la vida" y de las nuevas condiciones de posibilidad (JAMESON, 2012a, p. 129).

Ante el interrogante de cómo dicha época se veía a sí misma y percibía los avatares del Sueño Americano, creo entonces que la televisión ocupa un lugar privilegiado. Incluso, la apuesta teórica de Jameson sugiere que la respuesta misma puede ser hallada en las series televisivas y 
[...] en la representación de la cultura masiva, la única forma de arte que puede hacerlo y está dispuesta a lidiar con las realidades eisenhowerianas sofocantes de la familia feliz en el pueblo pequeño, de la normalidad y la vida cotidiana que no se aparta de la norma." (JAMESON, 2012b, p. 38).

En tal sentido, el filósofo convoca a no mirar con desdén las formas de consumo, dado que ellas son capaces de recomponer las contradicciones sociales a través de múltiples alegorías, estilizaciones y parodias, lógica que las series también heredan de la literatura folletinesca6. Una postura similar mantiene Alan Yentob, quien no duda en afirmar que, cuando la gente se cuestiona por la significancia del Sueño Americano, la solución se encuentra en el primetime, franja del consumo televisivo que se define por un número de audiencia elevada a millones ${ }^{7}$. Desde esta perspectiva, las grandes ficciones producidas a mediados de siglo por cadenas como National Broadcasting Company (NBC), Columbia Broadcasting System (CBS) y American Broadcasting Company (ACB) ofrecen un recorrido puntual para explorar algunas derivas de este imaginario.

Un buen ejemplo para inaugurar esta empresa es Father Knows Best, exitosa serie emitida entre 1954 y 1960 por la CBS. En formato sit-com (y aun en blanco y negro), la ficción relata la vida de los Anderson y los problemas cotidianos que atraviesan, resueltos siempre por la cabeza de la prole, porque, como bien reza el título, papá lo sabe todo. La serie no dudó en reforzar la axiología tradicional del hogar de clase media (la cultura del trabajo, los lazos vecinales, el respeto por la nación), contextualizando este entramado, como es de esperarse, en un pequeño suburbio. También, en Father Knows Best, los roles sociales se hallaban en armonía: un padre dedicado a su trabajo, una madre solidaria con la comunidad, y tres hijos responsables en el estudio. La serie giró en torno a pequeñas vicisitudes domésticas, estableciendo al núcleo familiar como marco general para el despliegue de veinticinco minutos diarios de relato. Sin dudas, todo estaba dispuesto para modelizar una cotidianeidad perfecta, con problemas nimios que adquirían, en este contexto, gran envergadura, aunque bien podían ser resueltos mediante el diálogo y la restitución de valores.

Por lo demás, el ejemplo es paradigmático, pero no el único. El "breve siglo" también se halla habitado por otros éxitos bien reconocibles, tales como la copiosa tribu de The

\footnotetext{
${ }^{6}$ Para una descripción del folletín como matriz de emergencia de las series (GÓMEZ PONCE, 2017, p. 90-95).

${ }^{7}$ Sigo las referencias del documental The United States of Television: America in Primetime, conducido por Alan Yentob, dirigido por Lloyd Kramer y emitido en 2013 por la BBC Two. Asimismo, los episodios "El hombre de la casa" ("Man of the House"), "Los inadaptados" ("The Misfits"), y "La mujer independiente" ("The Independent Woman") funcionan como grandes zonas problemáticas que, actualizadas a los objetivos de este trabajo, me permitirán ilustrar una genealogía televisiva del Sueño Americano.
} 
Las series y el Sueño Americano. Nostalgia y pervivencia de um imaginário suburbial.

Brady Bunch (1969-1974) o, más tardíamente, el asentamiento en Minnesota de la parentela de Little House on the Prairie (1974-1982, mejor conocida como La Familia Ingalls). La pregunta que surge es si estos sucesos (de gran repercusión en Latinoamérica) funcionaron como un reflejo del Sueño Americano, o bien como una pedagogía social que direcciona cambios en la familia promedio y su inserción cultural. En palabras de Jorge Carrión, se trata de diagnosticar cuánto colaboraron estos productos televisivos con un proceso de normalización, ya que las series habrían prefigurado modelos culturales “[...] televisivamente a la masa, para que esta comprenda que lo que en el ámbito de la Ficción era normal también podía serlo en el de lo Real” (CARRIÓN, 2014, p. 27). Y, según mi lectura, esta encrucijada se resuelve, de manera impensada, durante el mismo periodo en cuestión.

Figura 3 - De izquierda a derecha: póster promocional de Father Knows Best (Serie de Televisión), Ed James (Creador), Rodney-Young Productions / Screen Gems Television, CBS, 19541960; The Brady Bunch (Serie de Televisión), Sherwood Schwartz (Creador), Paramount Domestic Television, ABC, 1969-1974; y Little House on the Prairie (Serie de Televisión), Blanche Hanalis (Creador).
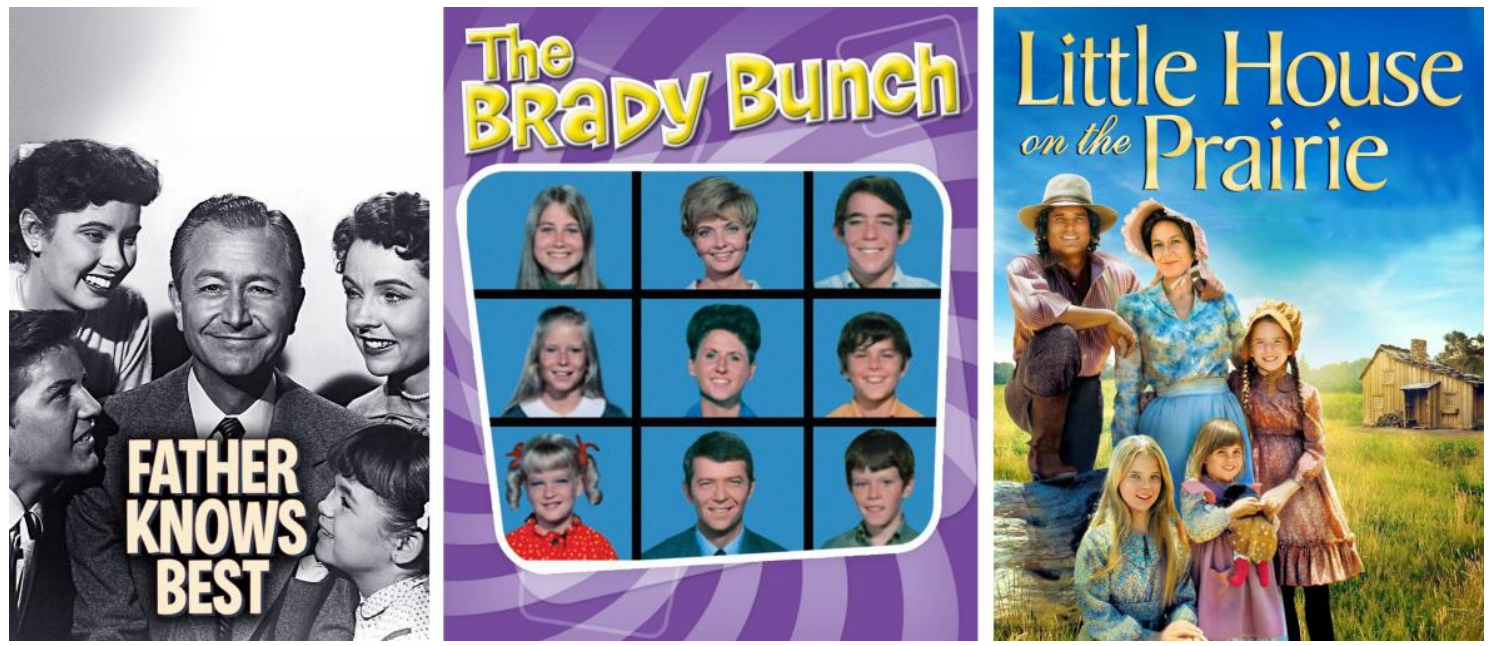

Fuente: Paramount Pictures, NBC (1974-1982).

Pues, al atender las series que bucean por el "breve siglo", se puede observar que el modelo estereotípico de familia es, tempranamente, disputado. Tomemos por caso The Beverly Hillbillies (1962-1971) con su historia de los Camplett, una familia montañesa que deviene millonaria gracias al encuentro accidental de petróleo. Al tiempo que pone en tela de juicio una cultura de la meritocracia (ya que el azar no es uno de los engranajes del Sueño Americano), el relato introduce costumbres y prácticas de una clase baja (reconocida, despectivamente, como "white trash" -"basura blanca"-) en un entorno elitista. Lo que dicha contradicción pone en escena es la existencia sincrónica de distintos estratos 
socioeconómicos en este periodo, deslizando otras formas de normalidad factibles. Vale decir que la serie propone lo "normal" como un concepto mutable que se define dentro en propias sus condiciones de posibilidad.

Y, aunque ciertos motivos del imaginario suburbial se respetan (hay un territoriohogar, un clan-familia y un cúmulo de valores -o, más bien, contravalores- que le son propios), The Beverly Hillbillies expone un precoz intento por desarticular una estandarización canónica: los Clampett, con su vida desorganizada y ruidosa, con su carreta destartalada y sus animales de granja, irrumpen en el paisaje límpido de las periferias para erosionar la perfección suburbial. Tomando las palabras de Jameson, se trata de una intrusión que responde, más bien, a un signo de protesta

[...] en contra del pueblo pequeño estadounidense complacido y hermético (blanco, de clase media), en contra del etnocentrismo conformista y centrado en la familia de un país próspero que aprendía a consumir durante el primer boom grande luego de la escasez y las privaciones de la guerra. (JAMESON, 2012b, p. 38).

También, el monstruo emergerá en este intento de quiebre de la estandarización, a través de un fuerte desplazamiento cultural que bien lo ejemplifica The Munsters (19641966): clan que reúne vampiros, hombres-lobo y otras criaturas fantásticas, bajo la tutela de un Frankenstein amigable. En dicha serie, interesará especialmente la sobrina Marilyn, rubia universitaria de gran belleza que, a los ojos de sus parientes, no ingresa en la idea de esta "normalidad" que construye la familia monstruosa. Algo similar sucede con la competencia directa de este seriado: los mortuorios The Addams Family (1964-1966), serie que reelabora en clave paródica los valores estándar de la comunidad en un hogar suburbial que roza lo gótico. Cabe recordar que, para Rosalba Campra (2008), esta "ruptura del silencio" del monstruo viene a sintomatizar un giro antropológico, vinculado con el reconocimiento de alteridades que han adquirido visibilidad social: si, hasta hace algunas décadas, esta criatura ocupaba un lugar antagónico y su discurso era solo referido por la voz humana, los grandes movimientos activistas y las luchas sociales abren la posibilidad de que múltiples discursividades-otras emerjan a la superficie, incluso en los géneros fantásticos. 
Figura 4 - De izquierda a derecha: captura de pantalla de The Beverly Hillbillies (Serie de Televisión), Paul Henning (Creador), Filmways Television, CBS, 1962-1971; imagen promocional de The Munsters (Serie de Televisión), Allan Burns (Creador).
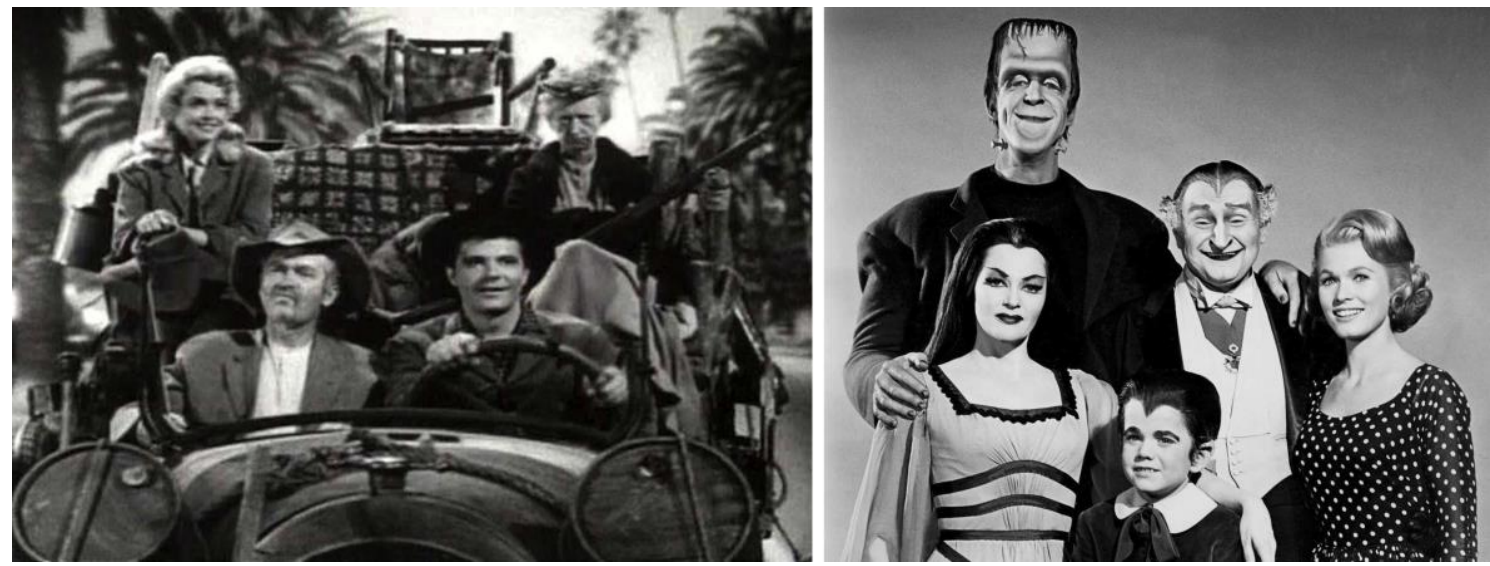

Fuente: NBC Universal Television Distribution, CBS (1964-1966).

Algo similar sucede con en relatos como Bewitched (1964-1972) o I Dream of Jeannie (1965-1970) donde Samantha, una bruja sagaz, y Jeannie, una genia milenaria, intervienen en la iconografía del matrimonio y expresan, además, un desplazamiento interesante en los roles sexuales. Pero, para explicitar esta cuestión, tal vez sea conveniente remitir a otro texto incluso anterior a Father Knows Best: I Love Lucy (1951-1957), con la hilarante Lucille Ball bajo el rol de una mujer aparentemente ingenua, esmerada en salir de su rol de ama de casa y hacer carrera como artista (aunque bien no cuente con ningún dote escénico). Pese a fracasar en su contienda, Lucy explora diariamente la posibilidad de ser una mujer independiente, rompiendo con aquella pasividad robótica de lo femenino suburbial y demostrando que la cultura del esfuerzo no es un dominio exclusivamente masculino. Incluso, la serie trabaja los tránsitos interculturales con su marido cubano que, persiguiendo el tradicional Sueño Americano del inmigrante, ha llegado a los Estados Unidos a probar suerte con su banda musical. Lucy, como también Jeannie y Samantha, interpela al matrimonio como una arena de lucha, dentro de la cual los hombres deben rescatar a sus contrapartes de constantes aprietos, mientras ellas aprenden a manipularlos para lograr sus cometidos. La fricción de los sexos aparecería, entonces, como síntoma de una tensión precoz, mostrando una conflictividad con las subjetividades canónicas que el suburbio propone en sede doméstica, y reafirmando, con ello, la hipótesis sobre los géneros y el retorno de la guerra que comentara líneas arriba. 
Figura 5 - De izquierda a derecha: imagen promocional de uno de los capítulos icónicos de I Love Lucy (Serie de Televisión), Jess Oppenheimer y Desi Arnaz (Creadores), Desilu Productions, CBS, 1951-1957; captura de pantalla de la introducción a Bewitched (Serie de Televisión), Sol Saks

(Creador), Screen Gems / Ashmont Productions, ABC, 1964-1972; captura de pantalla de la introducción a I Dream of Jeannie (Serie de Televisión), Sidney Sheldon (Creador).
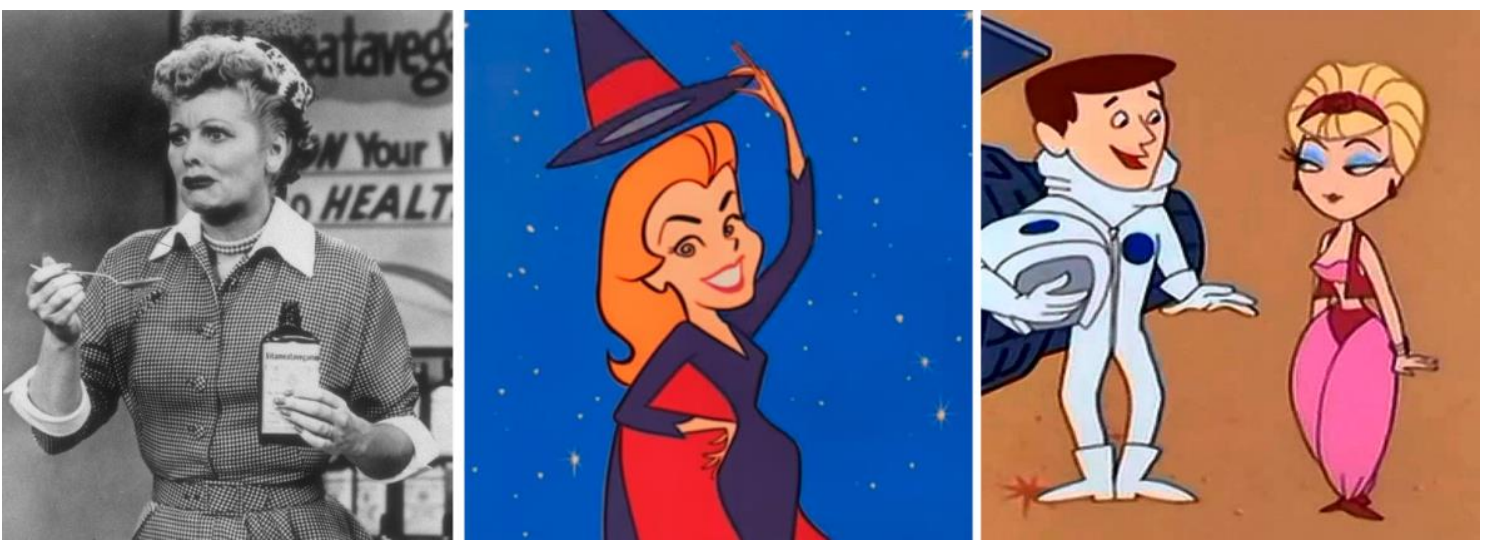

Fuente: Sidney Sheldon Productions / Screen Gems, (NBC, 1965-1970).

De modo que, para una lectura disfuncional del Sueño Americano suburbial, no deberemos esperar hasta la llegada de grandes relatos como Married... With Childen (19861997) o incluso The Simpsons (animación que, como bien reconoció su creador, pretende parodiar a Father Knows Best), puesto que ciertas matrices rupturistas empiezan a deslizarse en el nacimiento mismo de la serie como género masivo. No obstante, en todos los casos, una cuota de tradición es respetada, dado que la comunidad doméstica se mantiene siempre, más allá de las derivas que pueda adquirir. En efecto, la familia será el núcleo central de este imaginario onírico, estableciéndose ella dentro de un territorio específico, ora a la forma de un hogar, ora de cualquier espacialidad que materialice el Sueño Americano. También, estas series deben problematizar ciertas categorías volitivas, necesarias tanto para el desarrollo de su relato como para la culminación de un estereotipo de vida (norte)americano: ello es, un conjunto de valores preestablecidos en el foro interno de la familia, vinculados al trato entre los pares, la prevalencia primordial de la prole y el legado para la descendencia.

Casualmente, es en este punto donde la noción de nostalgia jamesoniana cobra relevancia. Porque, al establecer la familia como el núcleo central del Sueño, y al presentar diversas manifestaciones de ella, las ficciones estadounidenses dan cuenta de un motivo potente: la familia no interesa tanto en su constitución biológica, como en su conformación conceptual. Dicho de otro modo, importa una noción común de un "nosotros", priorizando con ello un modelo de comunidad, con sus propias micropolíticas y lazos sociales. Para ilustrar esta cuestión, basta recordar series más recientes como The Walking Dead (2011- 
2021), la cual adoctrina con una idea de colectivo que debe prevalecer ante toda tempestad, y donde la plaga zombi impulsa a los sujetos a agruparse en nuevos colectivos, en vistas de sobrevivir. Sin ningún tipo de vinculación consanguínea, los personajes de esta ficción se ven motivados a congregarse en pequeños grupos que toman la forma de una familia, en cierto modo para subsanar la pérdida trágica de sus seres queridos. Algo similar sucede con The 100 (2014) o la hoy clásica Lost (2004-2010), tal vez porque los géneros postapocalípticos muestren con mayor pregnancia la relevancia de resguardarse en una manada ante nuevas formas del darwinismo social.

No obstante, otras matrices genéricas aplicarán a la misma idea. Aunque de ningún modo sería pertinente desviar este recorrido (puesto que los ejemplos son profusos), vale la pena señalar series como Glee (2009-2015) o, en un tono más violento, 13 Reasons Why (2017-2020), pobladas por los desplazados de la escuela secundaria. En ellas, la comedia y el drama sacan a relucir las dimensiones más discriminadoras de la sociedad estadounidense, pero reforzando también la posibilidad de crear otras comunidades periféricas: otras "familias" donde resguardarse, subsistir a la cotidianeidad y revitalizar los valores americanos. De modo especial, será la problemática de la supervivencia aquella que aflore en estos relatos, lógica parecida a la que exponen, en clave económica, los custodios del modelo familiar tradicional. Cabe recordar, en este sentido, casos extremos como Breaking Bad (2008-2013) o Ozark (2008) donde, corrompiéndose en el proceso, los padres recurren a la criminalidad para proveer a sus familias. También, Weeds (2005-2012) organizará una narrativa similar, aunque abordándola desde la óptica de su contraparte femenina: la reciente viuda que, para abastecer a sus hijos, comienza a vender drogas a sus vecinos de los suburbios.

Como se comprenderá, es en estas derivas recientes de lo familiar donde afloran las fisuras del Sueño Americano y las falencias del simulacro. Porque, camuflados al amparo de la normalidad suburbial, estos personajes enfatizan los miedos del pequeño burgués y el brío por alcanzar, a toda costa, este imaginario, prevaleciendo siempre una concepción de bienestar económico. 0, quizá, sería más apropiado discernir aquí otras de las fuerzas ideológicas del imaginario (norte)americano, mediante la cual el núcleo familiar deviene metonimia de la nación: cuando la sociedad se derrumba, y sus códigos de convivencia desaparecen, la responsabilidad tiene que recaer en los habitantes. Y aquel espíritu nacionalista que mencionara líneas arriba reaparece en estos contextos ficcionales, para dar cuenta de que el sistema ideológico estadounidense funciona tan bien, que un puñado de sujetos serían capaces de reconstruir la nación dentro en un pequeño territorio (lógica que 
The Walking Dead explora temporada a temporada), aunque ello implique corromperse durante el proceso. Se trata de una fuerte disquisición en torno al carácter democrático de los Estados Unidos, territorio fértil que las series aún están abonando mediante el diagnóstico de síntomas duales: es decir, "muestran un inconsciente colectivo que se encuentra en el proceso de tratar de identificar su propio presente, al mismo tiempo que iluminan el fracaso de este intento, que parece reducirse a la recombinación de diversos estereotipos del pasado" (JAMESON, 2012b, p. 58).

\section{Conclusiones}

Más allá del terreno de las conjeturas, lo que esta incursión superficial ha demostrado es una sólida intromisión del Sueño Americano en materiales estéticos, tanto pretéritos como actuales. Esquirlas de sentido de su faceta suburbial permanecen en la memoria cultural, dando lugar a diferentes motivos que, in crescendo, han estado mutando en los derroteros de la televisión estadounidense: ese lenguaje cultural que (como el mismo suburbio) nace del entramado del capitalismo tardío. Como un periodo de abundancia y crecimiento, la vida suburbial deviene ese contexto predilecto que ha dejado sus huellas en la memoria social, direccionando el modo en que los textos son capaces de recomponer el imaginario fundacional de un país. Es en este sentido que, parafraseando a Fredric Jameson, las series contemporáneas podrían definirse como "series de la nostalgia": en ellas, ideas sobre el pasado se revelan de manera alegórica, como imágenes residuales gestadas durante aquel "breve siglo" sobre las cuales el presente le ha impuesto otra línea de significación.

Se podría hablar, entonces, de una nostalgia que responde a la utopía de la pequeña comunidad como única alternativa para subsistir y alcanzar, una vez más, la prosperidad. No obstante, he observado que se trata de un enclave que las series han disputado tempranamente, atendiendo a ciertas fisuras en una homogeneidad social, por lo demás siempre imposible. La televisión está demostrando que quizá la pregunta no es tanto "qué significa el Sueño Americano", sino más bien cuáles son los contextos que permiten que ciertos espacios sean asumidos como oníricos y utópicos. Porque la espacialidad parece ocupar un lugar preponderante en estos derroteros de lo cotidiano y del orden familiar como emblemas de la ideología estadounidense, expresando con ello que son los espacios de lo íntimo, en donde más se ponen en cuestión los mecanismos de control y normalización en las series contemporáneas (CARRIÓN, 2015). 
No debe olvidarse, finalmente, que las series son vehículos de sentidos culturales y que, por su masividad y éxito internacional, están construyendo una imagen de sociedad estadounidense que será percibida por el mundo. Si, como piensa Jorge Carrión (2014, p. 36), "la cultura estadounidense que presenta [la serie] es examinada por el espectador internacional desde una actitud proclive al análisis y al cuestionamiento", corresponde interrogarse cuál es, efectivamente, la percepción que el terreno estético está ofreciendo. Dicho de otro modo, ¿a qué visión del Sueño Americano están aplicando las series televisivas? ¿Se trata de una crítica efectiva a este imaginario de larga tradición, a sus fisuras y al precio que reclama para alcanzarlo? ¿0 estos reiterados reproches son, más bien, aquello que permiten su supervivencia: ello es, un imaginario que se deja someter a una discusión constante para que, finalmente, sigamos hablando de él?

Se trata de una encrucijada productiva que esta exploración permitirá situar en futuras investigaciones, en las cuales un análisis profundo y pormenorizado de las ficciones debe realizarse. En esa lectura, el modelo de familia suburbial funcionará como un pivote de suma importancia para comenzar un cuestionamiento más profundo de los avatares que la sociedad estadounidense desarrolla en su interior. También, supone un territorio fértil para interpelar al Sueño Americano como un modelo exportable en las series de TV y entender cómo los Estados Unidos están reconstruyendo su historia y su propio devenir. Pues, tal vez, sean las series quienes, finalmente, están escribiendo esa Gran Novela Americana a la luz de un presente dinámico y repleto de incertidumbres.

\section{Referências}

ARÁN, Pampa. La herencia de Bajtín. Reflexiones y migraciones. Córdoba: Editorial CEA, 2016.

BAIRATI, Piero. La città nord-americana. In: ROSSI, Pietro (coord.). Modelli di città.

Strutture e funzioni politiche. Torino: Einaudi, 1987.

BEWITCHED. Creación: Sol Saks. Estados Unidos, NBC Productions, 1974-1982. Serie de televisión.

BENDER, Thomas. Historia de los Estados Unidos. Una nación entre naciones. México: Siglo XXI, 2011.

BIG LITTLE LIES. Creación: David E. Kelley. Estados Unidos: Pacific Standard, Blossom Films, HBO, 2017-2019. Serie de televisión.

BOSCH, Aurora. Historia de Estados Unidos. 1776-1945. Barcelona: Crítica, 2010. 
BREAKING BAD. Creación: Vince Gilligan. Estados Unidos: Gran Via Productions, Sony Pictures Television, AMC, 2008-2013. Serie de televisión.

CAMPRA, Rosalba. Territorios de la ficción: lo fantástico. Madrid: Editorial Renacimiento, 2008.

CARRIÓN, Jorge. Teleshakespeare. Las series en serio. Buenos Aires: Interzona, 2014.

CARRIÓN, Jorge. La mirada masculina y la mujer moderna: de Mad Men a Masters of Sex. In: CRISÓSTOMO, Raquel; ROS, Enric (coord.). Mad Men. 0 la frágil belleza de los sueños de Madison Avenue. Madrid: Errata Naturae, 2015.

CASTORIADIS, Cornelius. Figuras de lo pensable. Madrid: Frónesis Cátedra, 2000.

CULLEN, Jim. The American Dream: A Short History of an Idea that Shaped a Nation. New York: Oxford University Press, 2003.

DESPERATE HOUSEWIVES. Creación: Marc Cherry. Estados Unidos: Universal Studios, ABC Studios, ACB, 2004-2012. Serie de televisión.

DUHAU, Emilio; GIGLIA, Ángela. Las reglas del desorden: habitar la metrópoli. México: Siglo XXI, 2008.

EDELSTEIN, Sally (comp.). Envisioning the American Dream (catálogo de imágenes). Estados Unidos, 2021. Disponible en: https://envisioningtheamericandream.com/

FATHER KNOWS BEST. Creación: Ed James. Estados Unidos: Rodney-Young Productions, Screen Gems Television, CBS, 1954-1960. Serie de televisión.

GIL CALVO, Enrique. Máscaras masculinas: héroes, patriarcas y monstruos. Barcelona: Anagrama, 2006.

GLEE. Creación: Ryan Murphy. Estados Unidos: 20th Century Fox Television, Ryan Murphy Television, FOX, 2005-2009. Serie de television.

GÓMEZ PONCE, Ariel. Depredadores. Fronteras de lo humano y series de TV. Córdoba: Babel, 2017.

GÓMEZ PONCE, Ariel. Pequeñas grandes mentiras. Narraciones seriales en torno al American Dream. Revista Representaciones, Córdoba, v. 13, n. 1, p. 109-126, 2018.

GONZÁLEZ ORDOVÁS, María José. Políticas y estrategias urbanas. La distribución del espacio privado y público en la ciudad. Caracas: Editorial Fundamentos, 2000.

HAGEDORN, Roger. Doubtless to be continued. A brief history of serial narrative. In: ALLEN, Robert (ed.). To Be Continued... Soap Operas around the World. New York: Routledge, 2001.

I DREAM OF JEANNIE. Creación: Sidney Sheldon. Estados Unidos: Sidney Sheldon Productions, Screen Gems, NBC, 1965-1970. Serie de television. 
I LOVE LUCY. Creación: Jess Oppenheimer y Desi Arnaz. Estados Unidos: Desilu Productions, CBS, 1951-1957. Serie de televisión.

JAMESON, Fredric. Documentos de cultura. Documentos de barbarie. Madrid: Visor, 1989.

JAMESON, Fredric. Posmodernismo. La lógica cultural del capitalismo tardío. Vol. I. Buenos Aires: La Marca, 2012a.

JAMESON, Fredric. Posmodernismo. La lógica cultural del capitalismo tardío. Vol. II. Buenos Aires: La Marca, 2012b.

JAMESON, Fredric. El posmodernismo revisado. Madrid: Abada Editores, 2012c.

LITTLE HOUSE ON THE PRAIRIE. Creación: Michael Landon. Estados Unidos, NBC Productions, 1974-1982 (serie de televisión).

LOST. Creación: J.J. Abrams. Estados Unidos, Bad Robot Productions, Touchstone Television, ABC, 2004-2010 (serie de televisión).

MARRIED... With Children. Creación: Michael G. Moye. Estados Unidos: Embassy Communications, Columbia Pictures Television, FOX, 1986-1997. Serie de televisión.

NIVÓN BOLÁN, Eduardo. Las contradicciones de la ciudad difusa. Alteridades, Iztapalapa, $n$. 13, v. 26, p. 15-33, 2003.

OZARK. Creación: Bill Dubuque. Estados Unidos: Aggregate Films, Zero Gravity Management, Netflix, 2008. Serie de televisión.

PINTOR IRANZO, Iván. Nunca volveremos a casa: la figuración del hogar en Mad Men. In: CRISÓSTOMO, Raquel; ROS, Enric (coord.). Mad Men. 0 la frágil belleza de los sueños de Madison Avenue. Madrid: Errata Naturae, 2015.

SECRET AND LIES. Creación: Timothy Busfield. Estados Unidos: Avenue K Productions, Hoodlum Kapital Entertainment, ABC, 2014-2015. Serie de televisión.

SEX AND THE CITY. Creación: Darren Star. Estados Unidos: Darren Star Productions, Warner Bros, HBO, 1998-2004. Serie de televisión.

STEVENS, Dana. The Good Wife. Slate, edición digital, 2004. Disponible en: https://slate.com/culture/2004/10/abc-s-unrealistic-desperate-housewives.html

SUBURGATORY. Creación: Emily Kapnek. Estados Unidos: Piece of Pie Productions, Warner Bros. Television, 2011. Serie de televisión.

THE 100. Creación: Jason Rothenberg. Estados Unidos: Alloy Entertainment, Warner Bros. Television, The CW, 2014. Serie de televisión.

THE ADDAMS FAMILY. Creación: David Levy. Estados Unidos: Filmways Television, ABC, 1964-1966. Serie de televisión. 
THE BEVERLY HILLBILLIES. Creación: Paul Henning. Estados Unidos: Filmways Television, CBS, 1962-1971. Serie de televisión.

THE BRADY BUNCH. Creación: Sherwood Schwartz. Estados Unidos: Paramount Domestic Television, ABC, 1969-1974. Serie de televisión.

THE MUNSTERS. Creación: Allan Burns. Estados Unidos: NBC Universal Television Distribution, CBS, 1964-1966. Serie de televisión.

THE STEPFORD WIVES. Direción: Frank Oz. Guión: Paul Rudnick. Estados Unidos: Paramount Pictures, DreamWorks Pictures, 2004. Basada en el libro "The Stepford Wives" de Ira Levin. Película.

THE WALKING DEAD. Creación: Fran Darabont. Estados Unidos: Valhalla Entertainment, AMC, 2010-2021. Serie de televisión.

13 REASONS WHY. Creación: Brian Yorkey. Estados Unidos: Anonymous Content, Paramount Television, Netflix, 2017-2020. Serie de televisión.

TOUS-ROVIROSA, Anna. Desde dentro del espejo. La construcción mediática del Sueño Americano. In: CRISÓSTOMO, Raquel; ROS, Enric (coord.). Mad Men. 0 la frágil belleza de los sueños de Madison Avenue. Madrid: Errata Naturae, 2015.

THE UNITED STATES OF TELEVISION. America in Primetime. Direción: Loyd Kramer. Conducción: Alan Yentob. Estados Unidos: BBC Two, 2013. Documental televisivo.

WEEDS. Creación: Jenji Kohan. Estados Unidos: Tilted Productions, Lionsgate Television, CBS, 2005-2012. Serie de televisión.

\section{A série e o Sonho Americano. Nostalgia e sobrevivência de um imaginário suburbano.}

\section{Resumo}

Na memória americana, a vida nos subúrbios continua sendo um contexto de prosperidade, fundamental para aquele imaginário conhecido como sonho americano. Não obstante, é um cenário idílico que as séries televisivas vêm questionando desde o próprio florescimento desse modo de viver. Este artigo propõe um estudo de ficções de meados do século passado que foram aplicadas a uma leitura disfuncional do sonho americano: ou seja, narrativas que conseguiram ilustrar os lados opostos da homogeneização e da padronização, revelando a ordem do cotidiano como um simulacro precário. No entanto, são motivos ideológicos que as produções mais contemporâneas parecem reler como uma "nostalgia": categoria que a teoria de Fredric Jameson desenvolve para desafiar formas artísticas onde as ideias do passado são elaboradas alegoricamente, como imagens. resíduos sobre os quais o presente impõe outra linha 
de significação. A proposta argumentará que as chaves para essa nostalgia devem ser rastreadas até o processo de suburbanização do pós-guerra, um enclave que não pode ser pensado fora de um capitalismo tardio incipiente cuja reprodução serial planejou tanto um projeto urbano quanto a conformação de subjetividades. Em diálogo com as contribuições de Jameson, o artigo pretende mostrar como, desde o início, a televisão de massa funcionou não apenas como um modo de produção estética, mas também como uma instituição social com força crítica.

\section{Palavras-chave}

TV series; American sonho; Suburban Imaginary; Fredric Jameson; Nostalgia

\section{TV Series and American Dream. Nostalgia and survival of a suburban imaginary.}

In American memory, life in the suburbs remains a context of prosperity, crucial to that imaginary known as the American Dream. However, it is an idyllic setting that television series have been questioning, even since the very flowering of this way of living. This article proposes a study of fictions from the middle of the last century that have been applied to a dysfunctional reading of the American Dream: that is, narratives that managed to illustrate the opposite sides of homogenization and standardization, revealing the order of the everyday as a precarious simulacrum. These are, however, ideological motives that the most contemporary productions seem to reread as a "nostalgia": a category that Fredric Jameson's theory develops in order to challenge artistic forms where the ideas of the past are elaborated allegorically, as images residuals on which the present imposes another line of significance. The proposal will argue that the keys to this nostalgia must be traced to the postwar suburbanization process, an enclave that cannot be thought outside of an incipient late capitalism whose serial reproduction planned both an urban project and the conformation of subjectivities. In dialogue with Jameson's contributions, the article aims to show how mass television has functioned not only as a mode of aesthetic production, but also as a social institution with critical force.

\section{Keywords}

TV series; American Dream; Suburban Imaginary; Fredric Jameson; Nostalgia 


\section{Autoria para correspondência}

Ariel Gómez Ponce

arielgomezponce@unc.edu.ar

\section{Como citar}

PONCE, Ariel Gómez. Las series y el Sueño Americano. Nostalgia y pervivencia de un imaginario suburbial. Intexto, Porto Alegre, n. 52, e-100603, jan./dez. 2021. DOI: http://dx.doi.org/10.19132/18078583202152.100603

Recebido em 19/02/2020

Aceito em 09/09/2020 